\title{
Entre as estatísticas e a cidade: o cadastramento e a produção da demanda social por apartamentos, no Programa Minha Casa Minha Vida
}

\author{
Between statistics and the city: enrolment \\ and production of social demand for apartments \\ in the Minha Casa Minha Vida housing program
}

Marcella Carvalho de Araújo Silva

\begin{abstract}
Resumo
Este trabalho investiga as controvérsias geradas pelo anúncio da remoção dos moradores de uma favela condenada por área de risco para um condomínio popular do Minha Casa Minha Vida. Com o intuito de compreender a contradição entre a produção de moradias e o recente aumento no déficit habitacional, este artigo foca no momento crucial da identificação do problema social no mundo, em que a abstração técnica do "risco" depende de classificações de situações concretas: 0 cadastramento social. Analisando os desacordos entre moradores que pretendem permanecer na favela e aqueles que pleiteiam a mudança, proponho uma reflexão sobre as dinâmicas do que estou chamando de um mercado imobiliário liminar, uma configuração espaço-temporal específica, entre a favela e o condomínio popular.
\end{abstract}

Palavras-chave: remoção; Minha Casa Minha Vida; cadastro social; mercados imobiliários informais; mercados imobiliários liminares.

\section{Abstract}

This paper analyses the controversies brought out by the announcement of the removal of dwellers of a slum located in a natural disaster risk area to a "popular condominium" of the Minha Casa Minha Vida Program in Rio de Janeiro. It aims primarily to understand the contradiction between the expansion of housing supply and the recent increase in the housing deficit. Thus, the core analysis focuses on the identification of the social problem in the world, in which the technical abstraction of "risk" depends on classifications of concrete situations: the so-called social enrolment. Investigating the disagreements unfolded between dwellers aiming to keep living in the slum and those willing to move to the apartments, this paper proposes a reflection on the dynamics of what I have coined liminal real estate market, a specific space-time configuration between the slum and the popular condominium.

Keywords: removal process; Minha Casa Minha Vida; social enrolment; informal real estate markets; liminal real estate markets. 


\section{Introdução}

0 Programa Minha Casa Minha Vida (doravante PMCMV) foi lançado em 2009 com a maior escala e volume de recursos já oferecidos em forma de subsídio à aquisição da casa própria para setores historicamente excluídos do mercado imobiliário formal. ${ }^{1}$ Com recursos do FGTS (Fundo de Garantia por Tempo de Serviço), SBPE (Sistema Brasileiro de Poupança e Empréstimo), FAR (Fundo de Arrendamento Residencial), OGU (Orçamento Geral da União) e FNHIS (Fundo Nacional de Habitação de Interesse Social), em suas fases 1 (2009-2011) e 2 (2011-2013), o Programa ofereceu subsídios a três faixas de renda familiar: subsídios integrais a famílias acometidas por desastres naturais; subsídios de $95 \%$ às famílias cujos rendimentos variam entre 0 a $R \$ 1.600$, a "faixa de interesse social"; e subsídios parciais àquelas cuja renda mensal fica entre $R \$ 1.600$ a $R \$ 3.100$ e $\mathrm{R} \$ 3.100,01$ a $\mathrm{R} \$ 5.000$, as duas últimas consideradas "faixas de mercado".

Contudo, a comparação entre estudos de 2008 e 2013 (mas referente aos dados do Censo 2010) da Fundação João Pinheiro sinaliza um aumento no déficit habitacional brasileiro: em 2008, o déficit era de cerca de 5,5 milhões de unidades habitacionais; em 2010, esse número subiu para cerca de 7 milhões de famílias sem casa, no Brasil. ${ }^{2}$ Como é possível que, após um ano de vigência da política habitacional mais significativa da história do país, o déficit habitacional tenha aumentado $?^{3}$

Para a compreensão dessa aparente contradição, em primeiro lugar, devemos problematizar a produção desses números. A estatística é uma linguagem consolidada e amplamente compartilhada no campo político. Como bem colocou Desrosières (2002), ela serve para denunciar problemas sociais, descrever interações econômicas e justificar ações políticas. Em diversos setores e especificamente naquele que nos interessa aqui, o conflito político passa pela disputa em torno das estatísticas. Elas, porém, são marcadas por paradoxo constitutivo: ao mesmo tempo em que o objeto dos conflitos são números que se pretendem confiáveis, a confiabilidade é posta em questão a todo momento (ibid., p. 12).

Com o intuito de compreender a controvérsia atual acerca da política habitacional - ou em outras palavras, da necessidade de se produzir casas, como e para quem construí-las devemos entender o processo de objetivação de fenômenos sociais em dados estatísticos. O IBGE define "família" como: "a) o conjunto de pessoas ligadas por laços de parentesco ou de dependência doméstica que morem no mesmo domicílio; b) pessoa que more sozinha num domicílio particular; c) conjunto de, no máximo, cinco pessoas que morem em um mesmo domicílio particular, embora não estejam ligadas por laços de parentesco ou de dependência doméstica" (Alves e Cavenaghi, 2004, p. 4). "Domicílio", por sua vez, é definido pelo IBGE como "o local ou recinto estruturalmente independente, que serve de moradia a famílias, formado por um conjunto de cômodos, ou por um cômodo só, com entrada independente, dando para logradouro ou terreno de uso público ou para local de uso comum a mais de um domicílio" (ibid.).

Ressalva seja feita que o censo domiciliar de 2010 mudou a relação entre família e domicílio, em comparação ao censo de 2000. Segundo recomendações da ONU de 2007, existem dois enquadramentos possíveis da relação 
família e domicílio: o de house-keeping, que privilegia a relação entre a renda e a moradia, e o de house-dwelling, que enfoca a unidade doméstica construída (Motta, 2014). Cada uma dessas perspectivas implica contabilizações distintas do problema do déficit habitacional e, consequentemente, a proposição de diferentes políticas habitacionais. Uma casa que abrigue, por exemplo, pai e mãe, um filho solteiro e um filho casado, cujo cônjuge viva sob o mesmo teto, seria considerada um problema de "coabitação", no primeiro caso. Desse ponto de vista, qualquer domicílio que abrigue mais de uma família que divida os custos da moradia é contabilizado no cálculo do déficit e torna-se, portanto, alvo da política habitacional de produção de novas unidades habitacionais. No segundo caso, a categoria "domicílio" prepondera sobre a de "família": o que importa é o espaço construído, independentemente de quem more lá. Esse mesmo caso hipotético seria contabilizado de forma diferente, não como duas famílias em situação precária, mas apenas uma. Em termos de política habitacional, esse cálculo pode desconsiderar a coabitação e criar um problema de superlotação de apartamentos em conjuntos habitacionais e condomínios populares. 0 cálculo do déficit habitacional que embasa o programa Minha Casa Minha Vida se pauta pelo segundo critério, de relação entre famílias e domicílios, mas a administração do programa se dá pela classificação da relação entre famílias e renda em diferentes "faixas".

Essa aparente dissonância pode ser meIhor compreendida se levarmos em consideração que o segundo desafio da atual política habitacional (e de qualquer política habitacional, necessariamente territorializada) é relacionar a estatística obtida pelas correlações entre famílias e domicílios à identificação dos segmentos da população sobre os quais 0 problema incide. Segundo os estudos da Fundação João Pinheiro, 70\% do déficit quantitativo incidem sobre a população cujos rendimentos variam entre 0 e 3 salários mínimos, o equivalente à faixa 1 do PMCMV. Localizar essa população se torna um desafio central ao programa. Na metodologia do Minha Casa Minha Vida, cabe aos municípios desenvolverem Planos Locais de Habitação de Interesse Social, que diagnostiquem de modo mais esmiuçado o déficit habitacional local e a relação entre as situações de moradia e as rendas das famílias. A localização espacial das famílias de baixa renda é então mediada por dois importantes instrumentos de imaginação urbanística, empregados para identificar no espaço as situações de precariedade: as "áreas de risco", conforme definição do Mapeamento de Riscos em Encostas e Margens de Rios, do Ministério das Cidades (2007), e os "aglomerados subnormais", ${ }^{4}$ definidos pelo IBGE.

Entre a representação do problema social e a projeção de ações de enfrentamento, há, portanto, que se compreender as mediações feitas entre o espaço social e o espaço urbano. Essa mediação é feita pelo cadastro social. Esse é um momento crucial do programa, pois é o cadastramento das famílias que cria a "demanda social", aquela referente à população de baixa renda, sobre a qual incide o déficit habitacional. Esse procedimento é muito mais complexo do que se supõe. É preciso compreender que entre a multiplicidade de casos singulares e a generalidade das categorias estatísticas existe um esforço classificatório, que enfrenta momentos de dúvida e controvérsias. Quem classifica? Quais são os critérios da 
classificação? Aquele que é classificado pode questionar a classificação que lhe é atribuída? Essas são todas perguntas relevantes à compreensão de como as operações classificatórias antecedem e criam as condições de possibilidade para as intervenções práticas.

0 cadastramento, para a faixa de interesse social, no programa Minha Casa Minha Vida consiste na elaboração de um "dossiê", junto às secretarias municipais de habitação. Os/As chefes das famílias pleiteantes devem apresen$\operatorname{tar}$ RG, CPF, certidão de casamento (quanto for o caso), comprovante de residência (emitido pela associação de moradores, na ausência de logradouro) e declaração de renda (sem a necessidade de comprovação com contracheque, já que há muitos casos de trabalhos informais).

Há dois tipos de cadastramento possíveis para a chamada "população de baixa renda": o "espontâneo", em que os próprios indivíduos pleiteiam o subsídio da compra de um apartamento; e o "social", em que as prefeituras devem fazer o mapeamento das "áreas de risco", elaborar um PLHIS - Plano Local de Habitação de Interesse Social, cadastrar in loco as casas a serem reassentadas e apresentar a resultante "demanda social" às empreiteiras, para que aí então sejam construídas as novas unidades habitacionais. ${ }^{5}$

0 procedimento de classificação que dá acesso ao subsídio dos apartamentos é feito pela equipe de trabalho técnico social das prefeituras e leva em consideração: a renda mensal das famílias; os critérios de prioridade determinados por cada município; e os cálculos dos déficits habitacionais quantitativos e qualitativos, desenvolvidos em parceria da Fundação João Pinheiro com o Ministério das Cidades, o Banco Interamericano de Desenvolvimento
(BID) e o Programa das Nações Unidas para o Desenvolvimento (PNUD), por meio do Programa Habitar/Brasil/BID. As prefeituras, responsáveis pela implantação do programa, se veem, então, diante da dificuldade de equacionar todos esses critérios e classificar situações indefinidas, que variam desde famílias com rendas superiores ao teto de $\mathrm{R} \$ 1.600$ vivendo em "áreas de risco" a famílias com renda muito baixa que não cumprem os critérios de prioridade do programa.

Com o intuito de compreender como se dá o processo de classificação do mundo dentro das categorias da administração, este artigo pretende, a partir de uma etnografia preliminar, ${ }^{6}$ refletir sobre as negociações e os conflitos desencadeados ao longo do processo de cadastramento de uma favela localizada em área de risco. ${ }^{7}$ Trata-se de uma pequena favela da Zona Norte da cidade do Rio de Janeiro, ${ }^{8}$ construída na beira de um rio, que nunca recebeu qualquer intervenção pública de urbanização. Ainda que haja postes da Light, o calçamento é todo fruto de mutirões. Essa favela está dividida em duas partes: uma mais larga e mais antiga, onde começou a ocupação do terreno nos anos 1960; e outra mais recente e estreita, cujas casas são as próprias paredes de contenção da água do rio. Em período de chuvas, não raro acontecem enchentes, que invadem casas e destroem os pertences das famílias.

\section{Casas marcadas para remoção}

As ameaças de remoção fazem parte da história dessa favela. Em um esforço de recuperar a memória de sua ocupação, em 2010, quando ela foi mais uma vez ameaçada de remoção, 
coletei inúmeros relatos sobre as estratégias empregadas ao longo dos anos pelos moradores para resistência: barricadas de mulheres e crianças, enfrentamento da polícia e dos tratores, negociações com parlamentares. Nesse mesmo ano de 2010, após intenso rebuliço e abaixo-assinado de moradores do "asfalto" do bairro, a remoção deixou de ser um assunto. Em 2012, ela reapareceu. Dessa vez, com força, por meio de boatos e "casas marcadas". "Um terrorismo", segundo Dona Catarina, uma das primeiras ocupantes da favela.

Exatamente por ter feito inúmeras entrevistas de história de vida com moradores da favela, fui chamada em 2013 a participar da resistência à remoção que, desde 0 ano anterior, vinha finalmente se concretizando. Em outubro, Dona Catarina pediu que eu Ihe entregasse nova cópia do CD com a gravação de suas memórias. Foi graças a esse recurso que fui apresentada à defensora pública, que já então se juntava à luta pela permanência da favela. Eu entro nessa história, portanto, como um instrumento de compilação da memória local, importante recurso de luta política. As minhas gravações são uma das tantas provas ${ }^{9}$ que os moradores vão mobilizar para questionar a justeza da medida de remoção: aquelas horas gravadas recontam o imenso investimento de tempo, afeto e dinheiro dos moradores da favela, para garantir um teto para si. Não era justo que a prefeitura os quisesse tirar.

Em 2012, a ameaça da chegada dos tratores atemorizou alguns moradores, que, receosos de perderem suas casas e ficarem sem lugar para morar, renderam-se à opção dada pela equipe de trabalho técnico-social da prefeitura de "trocá-las" por apartamentos em um condomínio popular, construído em bairro mais afastado do centro, também na Zona Norte. Segundo Dona Catarina, a associação de moradores foi decisiva nesse processo de convencimento dos moradores de que era melhor não resistir e aceitar "trocar a casa". "Uma expulsão", disse ela. Foi a associação que intermediou as negociações entre as agentes comunitárias da SMH e os moradores individualmente, "sem reunião, sem discussão com a comunidade". Segundo uma das fortes fofocas ${ }^{10}$ que circulam, ao presidente e ao vice foram dadas opções de indenização em dinheiro por suas casas e as de alguns familiares, opção negada aos demais moradores, que só poderiam "trocar a casa" por um apartamento.

A atuação da SMH se deu tanto por meio da marcação de casas com as inscrições "SMH-número", como pela presença de agentes comunitárias, dotadas de mapas, topografias e censos. Elas explicavam aos moradores o problema que as acometia e buscavam convencê-los de que os apartamentos do "condomínio popular" representavam "ascensão de vida" - "quem não quer morar em um apartamento, com a mesma infraestrutura de qualquer condomínio da Barra da Tijuca, guaritas, seguranças privados, portões, áreas de lazer e até 'espaço gourmet'?". Elas ainda mediavam a organização de visitas agendadas e guiadas pela prefeitura ao condomínio popular.

A mudança das primeiras 120 famílias fez da remoção dali em diante uma profecia que se autocumpria. As casas marcadas para remoção viraram casas abandonadas. Alguns moradores negociaram a demolição de suas antigas casas diretamente com a $\mathrm{SMH}$, produzindo ruínas em meio à favela, onde proliferaram ratos, insetos e lixo. Outras casas foram abandonadas e ocupadas por novos 
moradores, gente desconhecida que gerou desconfiança entre os "antigos".

Em meio a esse processo, os moradores que queriam permanecer na favela buscaram se mobilizar. Sr. Alberto, que se formou uma liderança ao longo do processo de resistência, entrou em contato com a Pastoral de Favelas, que sugeriu a formação de uma comissão de moradores imediatamente. Por meio da Pastoral, eles contataram o Núcleo de Terra e Habitação da Defensoria Pública. A essa "luta", agregou-se ainda um vereador do PT, com expressiva votação na região. Foi por ele que a comissão de moradores conseguiu solicitar à Comlurb a retirada do entulho das demolições já realizadas. Progressivamente, à comissão somaram-se outros moradores, o que foi gerando discordâncias internas quanto às estratégias a serem empregadas. Marta, funcionária do governo do Estado, muito mais jovem do que Dona Catarina e Sr. Alberto, em meio às eleições municipais de 2012, buscou o apoio de militantes do PSOL.

Entre as estratégias dispersas empregadas por membros da comissão de moradores, houve um primeiro empenho na construção de uma comunidade imaginada ${ }^{11}$ (Anderson, 2008) para a favela. Sr. Alberto desenhou uma bandeira que os representasse, lançando mão de alguns elementos da história de ocupação. Seu objetivo era, com a determinação da "soberania do povo", materializada na bandeira, estabelecer o domínio dos moradores sobre aquela porção de terra. Paralelamente, a comissão de moradores providenciou a instalação de uma placa, sinalizando, na rua principal mais próxima, a entrada da favela, tirando-a assim da invisibilidade. Ainda houve uma pontualíssima discussão sobre a apresentação de si como "comunidade" ou a autoproclamação como "condomínio", na tentativa de, mudando de nome, acabar com o problema. ${ }^{12}$ Mas de todas as estratégias, a mais importante foi a mediação da Defensoria Pública.

É importante destacar que a oposição entre moradores que querem permanecer e moradores que pretendem se mudar para 0 condomínio não nasceu imediatamente. Durante alguns meses, os próprios moradores que queriam ficar me levavam para conversar com moradores que queriam sair. A despeito das fofocas, havia um esforço coletivo de que cada família seguisse com sua vida como meIhor the aprouvesse. Moradores antigos com casas amplas e consolidadas entendem como perfeitamente justo que moradores de barracos de madeira - que ainda existem na favela ganhem um apartamento. Em um de nossos encontros, Sr. Alberto me conduziu por uma visita guiada por toda a favela e me apontou as tantas "casas boas", cujos valores não condizem a um apartamento, e também diversas casas precárias, cujas paredes fazem a contenção do rio, estão corroídas e são extremamente insalubres. A comissão não é contra os apartamentos em si. Como Ingrid, que também luta pela permanência, me colocou em uma longa conversa que tivemos em uma das lanchonetes da rua do comércio da favela, a prefeitura deveria "ajudar que cada um edificasse sua vida como quisesse". ${ }^{13}$

De modo a frear a remoção que já então se autocumpria, no final de 2013, a Defensoria conseguiu que fosse expedida uma liminar que condicionava a mudança para os apartamentos à elaboração de um plano de urbanização para os que ficassem. Esse seria o melhor acordo: contemplaria os casos de "risco" e de casas 
precárias, que a comissão de moradores reconhecia existirem; e contemplaria os moradores que autoconstruíram suas casas, investindo tempo, dinheiro, suor e afetos. Contudo, se se pretendia o mais justa possível, a liminar criou um forte impasse e a polarização dos dois grupos de moradores.

Num primeiro momento, no início de 2014, a Defensoria solicitou a assistência técnica de urbanistas do Ippur/UFRJ, ${ }_{1}^{14}$ para a validação da classificação feita pela Geo-Rio ${ }^{15}$ da intensidade dos pontos de risco e de sua localização na topografia da favela. Na visita das duas técnicas, uma legião de moradores foi se agregando ao pequeno grupo de técnicos e lideranças, ansiosa para saber se suas casas "estavam em risco mesmo" e se sairiam.

Os dilemas impostos pelo espaço construído da favela às duas urbanistas foram inúmeros. A elas cabia a tarefa de relacionar a topografia que a defensora conseguiu junto à prefeitura ao espaço vivido da favela. Para os moradores, a leitura dos mapas padecia de certo mistério. Mais do que uma visita técnica, foi preciso compreender os usos que eram dados àquelas construções e as relações entre elas. 0 que fazer com um centro comunitário antiquíssimo, no qual funcionam alguns projetos sociais, mas que está dentro do limite técnico de risco, dada a proximidade com o rio? Como conciliar a técnica e a política? Alguns pontos eram consensualmente entendidos como "risco", por urbanistas, lideranças e moradores que se somavam àquela caminhada de reconhecimento do espaço. Outros, contudo, eram alvos de controvérsias, pois a) do ponto de vista técnico, deveriam sair, em virtude da baixa incidência de luz e problemas de circulação de ar; b) estavam parcialmente em risco - uma pilastra ou apenas um cômodo dentro das áreas demarcadas, implicando perdas de espaço nas casas; c) eram construções geminadas - a demolição de uma implicaria a desestabilização de outra; e d) opunham o vizinho de cima que queria sair e o vizinho de baixo que queria ficar.

Após essa visita técnica, o plano de defesa dos moradores foi pleitear uma reorganização do espaço da favela: aqueles moradores da área do rio seriam remanejados para as moradias daqueles que já se mudaram para os apartamentos, e a área mais antiga e larga da favela seria urbanizada. Assim, as casas desocupadas não seriam reocupadas de forma desordenada ou virariam ruínas, acirrando, de forma não desejada, o processo de remoção.

Contudo, a espera pela concretização do plano de urbanização tem postergado as mudanças das 120 famílias já cadastradas no Minha Casa Minha Vida. Enquanto eles não mudam, não é possível reordenar o espaço da favela e começar as obras de urbanização. As fofocas e a tensão só aumentam, as expectativas e ambições dos dois grupos são frustradas. ${ }^{16}$

\section{As injustiças do cadastramento}

Ainda que as "áreas de risco" procurem reparar um problema social, elas não podem ser tomadas como dadas. A "área de risco" é uma categoria da ambientalização das lutas sociais (Acselrad, 2010), que engloba deslizamentos de terra e pedras, e enchentes de rio. Mais do que isso, ela deve ser entendida como uma racionalização administrativa, que procurou criar um instrumento técnico que permitisse a 
reparação da injustiça social da perda de casas por catástrofes naturais.

Aqui cabe resgatar a reflexão a posteriori de Cesar Benjamin sobre sua experiência como secretário de desenvolvimento social da prefeitura do Rio, em 1988, primeiro passo de uma genealogia que venho tentando desenvolver da problemática do risco como derivação da problemática da moradia. Em final de 1988, ele escreve um artigo sobre o principal problema a ser enfrentado pela urbanização: administrar a lógica do "sistema dominante" dentro da favela. 0 "direito à existência" das favelas implicava a consolidação de uma "burguesia favelada" (termo tomado de empréstimo de Machado da Silva, 1967), proprietária de casas, cômodos e quitinetes, e a conseguinte privação do "direito à favela" daqueles que viviam de aluguel. 0 conflito entre esses segmentos estratificados nas favelas seria, então, o motor da contínua favelização: a alternativa ao aluguel seria ou a migração para outras e novas favelas, ou a expansão das fronteiras das favelas consolidadas, com a ocupação de áreas precárias. Como a urbanização implicava a consolidação da lógica da mercantilização das casas, consequentemente, como efeito não previsto, havia a formação de uma "população mais empobrecida, menos enraizada e mais sujeita a riscos de diversos tipos, especialmente nas áreas de encosta" (Benjamin, 1988, p. 37). Ao longo de sua gestão, Benjamin procurou então compreender esse universo do "risco" e categorizá-lo.

Se a problematização e consequente elaboração de um regime de racionalidade para o risco criaram um instrumento técnico da mais alta valia para arquitetos e urbanistas, a identificação das áreas de risco esbarra em dificuldades políticas para sua operacionalização. 0 momento da identificação e seus critérios específicos criam inúmeras situações indeterminadas, de dissonância entre a generalidade da categoria "risco" e a singularidade das situações concretas das famílias. Da aplicação da categoria da administração no mundo nascem inúmeros conflitos entre os diferentes modos de classificar situações e pessoas (Boltanski e Thévenot, 2006). A análise da tematização das controvérsias daí geradas como injustiças permite compreender melhor as complexidades envolvidas na política habitacional.

Há ao menos três injustiças no processo de cadastramento social. Em primeiro lugar, as famílias residentes em áreas de risco não necessariamente concordam com essa classificação do lugar onde moram. Muitas já enfrentaram diversas enchentes, perdas de imóveis e pertences e se identificam com essa classificação técnica. Diversas outras, porém, resistem a essa classificação e alegam a dissociação entre a categoria da administração e sua experiência vivida. Esses moradores que não identificam suas casas como sujeitas ao risco, porém, podem muito bem reconhecer a identificação de outros. 0 reconhecimento do problema "área de risco" aparece muitas vezes combinado ao recurso de sua atribuição ao outro: o problema existe, entendo que haja situações em que é justo que os moradores sejam cadastrados no programa habitacional, mas esse não é o meu caso. E aqui surgem inúmeros esforços de diferenciação entre casos concretos, cujas estratégias passam pela valoração (simbólica e monetária) da casa, como Sr. Alberto fez em nossa visita guiada. 
Uma segunda injustiça é a dissonância entre situações de moradia e renda familiar. Há famílias com rendimentos superiores ao teto de $R \$ 1.600$ que se autoidentificam com a situação de risco e há também famílias com rendimentos inferiores que não se identificam, mas se encontram em situações objetivamente mais precárias. No primeiro caso, é preciso que, na elaboração do dossiê de cadastramento, as famílias declarem rendas inferiores aos seus rendimentos reais. Isso pode se dar de forma espontânea, por meio da simples omissão, principalmente daqueles auferidos da/na informalidade; ou de forma mais impositiva, por meio da ameaça de interrupção dos dossiês, enquanto as famílias não se enquadrarem como "população de baixa renda". Em um dos casos que acompanhei, um casal, nascido e criado na favela, teve que construir uma barreira de concreto na porta de casa, que impedisse o esgoto da vala em frente de entrar na sala. Além disso, a casa quase não recebia luz e a umidade estava deixando sua filha pequena com sérios problemas respiratórios. Como estavam ambos convictos de que deveriam sair da favela, a esposa decidiu pedir demissão de seu emprego formal e o casal declarou apenas o salário do marido. Posteriormente, essa decisão se mostrou problemática, devido à demora na mudança para o apartamento. Eles compõem a segunda leva de moradores, cujas mudanças ficaram embargadas até a apresentação de um plano de urbanização para a favela. Outro caso crítico era de uma senhora com baixíssimos rendimentos, cuja casa estava mais afastada da beira do rio. Afastada do "risco iminente", ela não teria tanta prioridade na mudança para o condomínio popular, o que era considerado uma injustiça inclusive por membros da comissão de moradores.

Uma terceira injustiça diz respeito aos comércios da favela, pois eles não são indenizados ou trocados por novos espaços nos condomínios populares, estritamente residenciais. Em meio à controvérsia da remoção da favela cujo caso embasa este texto, os comerciantes da rua de principal atividade econômica passaram a encarar dilemas familiares. Um deles é bastante emblemático: a casa do pai, como tantas nas favelas, foi fracionada em um comércio e em duas outras casas, assim que seus filhos se casaram. Uma única construção, portanto, continha uma loja e três casas independentes - ou três domicílios distintos, segundo os critérios do programa. Apesar de concordar com a classificação da sua moradia em área de risco, o pai passou a resistir à mudança para 0 apartamento, pois não seria indenizado por sua loja de material de construção, sua única fonte de renda. Sua filha e seu filho, por outro lado, queriam se mudar para seus apartamentos novos e sair da beira do rio.

\section{Entre a favela e o condomínio popular: os mercados imobiliários liminares}

Em sua pioneira pesquisa, de caráter compreensivo, sobre as remoções de favelas para o então recém-construído conjunto habitacional de Cidade de Deus, Valladares (1978) analisa as estratégias dos moradores de favelas, para resistir e para se apropriar da política habitacional. Sua etnografia trata as remoções 
como processos políticos altamente complexos e chama a atenção para sua dimensão econômica, pouco levada em consideração. Naquele momento, as discussões da sociologia urbana não levavam em conta o valor de troca da autoconstrução. ${ }^{17}$ Segundo o argumento inovador de Valladares, era exatamente o caráter de bem de capital da moradia popular que explicava a contradição que se enfrentava: a política habitacional alimentava a favelização que procurava combater, pois os moradores "passavam" as casas e os apartamentos novos, para fazer poupança, pagar dívidas ou investir em outras frentes (de moradia e trabalho).

Partindo da discussão proposta por Valladares, o primeiro passo da análise dos efeitos das políticas habitacionais atuais deve ser o reconhecimento da existência de mercados imobiliários informais nas favelas. Segundo moradores que pretendem sair da favela aqui estudada, alguns militantes de fora, ligados a movimentos sociais que se juntaram à resistência à remoção, só enxergam a urbanização como uma bandeira legítima, deixando de lado uma discussão sobre condições de habitabilidade. Uma moradora que paga aluguel por uma quitinete na favela e aguarda a liberação de seu apartamento questionou um militante que fazia uma fala combativa em uma reunião, se ele trocaria o apartamento dele "no asfalto" pela quitinete onde ela está residindo na beira do rio. Para os moradores que querem sair, a situação de precariedade onde vivem não é politicamente reconhecida, em virtude de uma romantização, alegam eles, sobre as relações entre os moradores de favelas, que passa tanto por uma exaltação acrítica de supostos vínculos comunitários, com os quais os próprios moradores não se reconhecem, como pela invisibilização dos mercados informais da favela.

A composição e os mecanismos próprios dos mercados imobiliários informais vêm sendo investigados, desde o reconhecimento, por parte de arquitetos e urbanistas, dos efeitos de valorização que políticas de urbanização acabam gerando. ${ }^{18} \mathrm{~A}$ mercantilização das casas não é criada pela política habitacional nas favelas. A invisibilidade e a desconsideração dos mercados imobiliários informais, em que a autoconstrução vira bem de capital e circula como mercadoria, não permite compreender a questão do patrimônio dos moradores das favelas e contribui para uma oposição reducionista entre aqueles que querem deixar a favela como "cooptados" e aqueles que querem permanecer como "resistentes".

Os mercados informais de solo são um dos principais mecanismos de acesso à terra urbana de uma parte considerável da população pobre das cidades latino-americanas, em geral, e brasileiras, em particular. Cerca de 22\% da população do Rio de Janeiro, por exemplo, mora em favelas ou loteamentos clandestinos (IBGE, 2010). Com a redução expressiva dos processos de ocupações de terras, em virtude da diminuição da oferta de espaços ociosos, os mercados informais de comercialização e locação se tornaram o principal mecanismo de acesso à moradia (Abramo, 2003).

Ao contrário do que se pensa sobre os mercados informais, existem atividades regulares de compra, venda e locação de imóveis. São mercados pujantes e independentes, que sofrem os efeitos de políticas de urbanização e de habitação, mas que funcionam a despeito delas. Em importante pesquisa sobre o funcionamento desses mercados, Abramo 
(2009) identifica que as principais ofertas de moradia se dão pelo fracionamento de lotes familiares, em favelas consolidadas, e pela pontual comercialização de lotes novos, em loteamentos clandestinos.

Especial atenção deve ser dada à locação informal. Em algumas capitais brasileiras, ela apresenta peso mais do que expressivo como forma de acesso à moradia: em Recife, 58\% do mercado informal são mantidos por aluguéis; no Rio, esse valor chega a 29\% (Abramo e Pulici, 2009). Mais significativo do que os números em si é o diagnóstico de crescimento substancioso do peso dos aluguéis nos mercados informais, entre 2002 e 2006, quando os valores no Rio dobraram. Em survey recente (Cavalcanti, no prelo), realizado em quatro favelas da Zona Oeste da cidade, exatamente na frente de expansão imobiliária, os números de aluguéis sobem ainda mais: $34 \%$ da população alugam o imóvel onde mora.

Além do seu peso cada vez mais expressivo, também é preciso compreender melhor as relações de locação informal em favelas. Pesquisa qualitativa recente em duas favelas que receberam intervenções do programa Favela Bairro indica que a locação já é a principal porta de entrada de novos moradores a algumas favelas e que 0 aluguel de quitinetes, por exemplo, é muito mais rentável do que a venda dos imóveis (Magalhães et al., 2013).

Por fim, é preciso analisar os mecanismos de construção social do valor em mercados informais e os efeitos de valorização de políticas urbanas. ${ }^{19} 0$ primeiro ponto a ser levado em consideração diz respeito ao valor de troca das casas e não apenas o seu valor de uso, o enorme apego que em geral as pessoas têm por aquilo que construíram ao longo dos anos. Alguns dos moradores que resistem à remoção gostariam de sair da favela. Não querem que a prefeitura lhes dite como e para onde, mas, para eles também, sair da favela significa ascensão social. Ingrid, membro da comissão, vinha, desde antes do anúncio da remoção, requerendo um empréstimo junto à Caixa Econômica Federal, para financiamento da compra de um apartamento em prédio próximo à favela. Ela seria mais um ator do mercado imobiliário limiar (Cavalcanti, 2010, 2014), não fosse a instalação de uma UPP na região e a elevação do preço dos imóveis além do que o seu salário e o do marido poderiam pagar. A mudança para um apartamento em um condomínio popular, em bairro mais distante, não é, contudo, o meio de realizar sua mobilidade social. Comparando o tamanho, a qualidade construtiva e a localização do apartamento à sua enorme casa de três andares e quintal murado, o casal não vê entre eles uma vantagem de mercado, sequer uma equivalência de valor. A vizinhança, as redes de solidariedade importam, mas há uma série de valorações em jogo: foram anos trabalhando para (e, às vezes, literalmente trabalhando na) construção daquele patrimônio. A área construída, a localização, os requintes de arquitetura e decoração e a "liberdade urbanística" de que fala Abramo (2003) - de construir "puxadinhos" e lajes, para uso familiar, comercialização ou locação valorizam-na muito além dos 60 e poucos metros quadrados dos apartamentos nos blocos pré-fabricados dos condomínios populares do Minha Casa Minha Vida, que sequer podem ser comercializados por um período de dez anos. Segundo alguns daqueles que lutam pela permanência me disseram, se a indenização ou o tamanho do apartamento fossem maiores, 
talvez se mudassem, como alguns filhos e vizinhos fizeram.

Do mesmo modo, é possível compreender a ação daqueles que se mudam para o apartamento. Eles percebem na "troca" um valor justo. Alguns alegam a precariedade de suas casas, como alguns barracos de madeira e muitas casas cuja parede é a única contenção do rio, pessoas que já "perderam tudo" com as enchentes e para as quais o apartamento significa "melhoria de vida". Outros veem na futura possibilidade de mercantilização do apartamento uma alternativa para acumular capital. Um morador que se mudou na primeira leva, mas que manteve o comércio na favela, já fez uma pesquisa de mercado, avaliando os valores dos apartamentos em outros empreendimentos subsidiados na mesma região do seu condomínio. Ele nutre a esperança de "fazer poupança", nos próximos anos. Para eles, como Valladares (1978) já havia destacado nos anos 1970, a moradia é também um bem de capital e não exclusivamente de consumo.

Como podemos perceber pelo caso da favela aqui analisada, assim como as próprias dinâmicas do mercado imobiliário informal se alteram com a mudança do horizonte de possibilidades, criada pelo anúncio do programa Minha Casa Minha Vida, as elaborações sobre o que significa "melhorar de vida" passam pela valoração comparativa entre a casa e o apartamento, a partir do emprego de diversos e complexos instrumentos de mensuração e também da avaliação da factibilidade da realização de projetos de vida.

Nesse sentido, de modo a compreender as dinâmicas complexas que perpassam a atual política habitacional, sugiro pensar os condomínios populares a partir do que estou chamando de mercados imobiliários liminares. Sua liminaridade diz respeito à suspensão do curso regular das dinâmicas dos mercados informais e subsequente evidenciação das regras de seu funcionamento, tal como no sentido da liminaridade proposta por Turner (1974, 1987). Os mercados imobiliários liminares são então concebidos como configurações espaço-temporais específicas, em que operam 1) os dispositivos da política habitacional, os múltiplos critérios de classificação da "população de baixa renda", o cálculo dos déficits habitacionais quantitativos e qualitativos, os critérios de prioridade que hierarquizam os beneficiários, em suma os instrumentos do cadastro social, que produzem a "demanda social"; 2) os mecanismos do mercado imobiliário informal, as estratégias de multiplicação de casas, a partir da máxima divisão de edificações em unidades domiciliares independentes, das ocupações de terrenos e/ou propriedades ociosos, das mudanças temporárias para quitinetes e casas alugadas, entre outras estratégias de maximização do número de apartamentos recebidos, ao longo cadastramento de beneficiários; e 3) os projetos das famílias, apreendidos a partir de suas narrativas sobre "melhorar de vida" e da avaliação comparativa entre o valor da casa e o valor do apartamento, com as devidas especulações e projeções sobre o futuro.

Os mercados imobiliários liminares são um objeto inspirado nos mercados imobiliários limiares, sugeridos por Cavalcanti (2010, 2014). Segundo a autora, os mercados limiares são configurações específicas, que têm a proximidade física entre a favela e o asfalto como um fator determinante. Eles são formados pela valorização dos preços dos imóveis no mercado informal, decorrentes de políticas 
de urbanização, de um lado, e pela desvalorização dos preços dos imóveis no mercado formal próximo a favelas, devido ao problema da segurança pública, de outro. A equivalência de valores pecuniários entre casas e apartamentos nos mercados limiares permite a "saída da favela", entendida como "melhoria de vida". A vizinhança com "favelados", contudo, é compreendida como um sinal da decadência de moradores de apartamentos do "asfalto", cujos preços diminuem substantivamente. Uma vez que os valores pecuniários se equivalem, as fronteiras entre a favela e 0 asfalto devem ser constantemente negociadas. Nesse sentido, os mercados limiares são um objeto da clássica sociologia econômica, que busca compreender os embasamentos sociais do mercado e principalmente os valores constitutivos do cálculo racional.

A proposição de mercados imobiliários liminares como um objeto pretende apreender as controvérsias geradas pela imposição de uma equivalência de valor entre casas e apartamentos, nos casos de remoções de áreas de risco. Nesses casos, com a impossibilidade de indenizações, as casas devem ser "trocadas" (termo nativo) pelos apartamentos. Contudo, como procurei demonstrar com o estudo de caso apresentado, não há consenso acerca da justeza da medida de "troca". Há aqueles que consideram os apartamentos além do valor das casas e outros que os consideram aquém. Como nessas trocas, as casas não chegam a ter valor pecuniário, os moradores mobilizam outros critérios para valoração da casa: os anos despendidos na autoconstrução, a estrutura e os requintes de acabamento, a localização na cidade. Dependendo do valor final que atribuam às casas, os moradores a) rejeitam a possibilidade de mudança e, se ela se efetiva mesmo a contragosto, consideram-na uma "remoção"; b) aceitam um único apartamento, considerando a "troca" justa; ou c) desenvolvem táticas que burlam a equivalência abstrata entre uma casa e um apartamento, dividem suas casas com baias em inúmeras unidades habitacionais derivadas (domicílios independentes, para o PMCMV) e, assim, maximizam o número de apartamentos recebidos, criando, portanto, eles mesmo a equivalência "justa". São essas dinâmicas que tornam a mudança para um apartamento positiva ou negativa. Para famílias que já perderam suas casas inúmeras vezes em desabamentos e/ou enchentes e para aquelas que vivem de aluguel, o apartamento tende a ser visto como uma "melhoria de vida". Para aqueles que tinham "casas grandes" e "casas boas", com acabamentos requintados, muitos quartos e banheiros, o apartamento é uma "decadência".

\section{Algumas luzes dos mercados imobiliários liminares}

Deslocamento no espaço. Minha inserção nas lutas da comissão de moradores anteriormente narradas foi pontual e sem pretensões acadêmicas. Parte do trabalho de campo de minha tese de doutorado foi realizada em Parque São José, município de Duque de Caxias, Região Metropolitana do Rio, onde acompanhei sistematicamente o trabalho da equipe técnico-social da Secretaria Municipal de Planejamento, Habitação e Urbanismo, relativa à fase de ocupação dos condomínios, posterior ao cadastramento. A experiência de uma moradora de 
um desses condomínios populares resume bem a complexidade da dinâmica nos mercados imobiliários liminares.

Suzy pagava $\mathrm{R} \$ 120$ por uma "quitinete mofada" na favela Barreira do Pilar, onde vivia com os dois filhos. Conseguia pagar o aluguel graças ao incremento de renda do Bolsa Família. Desde que sua filha mais velha adoeceu, sua vontade de sair da favela aumentou imensamente. Segundo ela, houve muita "injustiça" nos sorteios precedentes, que beneficiaram "muita gente que não precisa". Por isso, ela resolveu mostrar que "precisava mais". Acampou com outros moradores do Pilar em frente à prefeitura de Caxias, levando a filha doente nos braços. Suzy não participou de uma ocupação de propriedade ociosa realizada por moradores, pois considerava sua "necessidade" menor do que a dos "invasores" - o Bolsa Família ainda dava conta de arcar com suas despesas. Após alguns dias acampada, ela conseguiu um "encaminhamento institucional" direto do gabinete do prefeito e a prioridade no cadastramento. Em pouco tempo, conseguiu uma "casa digna", onde sua filha doente pudesse morar.

Em sua conversa com a equipe de trabaIho social, Suzy mostrou veementemente sua indignação com as "injustiças" do processo de ocupação dos condomínios. Segundo ela, são duas as principais: o sorteio de pessoas "sem necessidade", que têm "casa boa" (na favela), e os apartamentos vazios. Em alguns casos, ${ }^{20}$ esses problemas estão relacionados, acirrando as indignações. Em um dos apartamentos do seu bloco, a beneficiária "não tinha necessidade" de um apartamento, por ter "casa boa" na favela. Mesmo em se tratando de área de risco, em virtude dos constantes tiroteios locais, a prefeitura não demoliu as casas de todos aqueles contemplados pelo PMCMV. Essa vizinha de Suzy mantém o apartamento fechado, se beneficiando do cartão Minha Casa Melhor, enquanto busca um locatário. Uma das amigas próximas de Suzy, por outro lado, ainda não foi sorteada e continua pagando $\mathrm{R} \$ 150$ para viver com os cinco filhos em um terraço na Barreira do Pilar.

Esse relato contém alguns dos principais aspectos da complexidade do Minha Casa Minha Vida. Em primeiro lugar, ele sinaliza as diferentes narrativas relacionadas à obtenção de um apartamento. Na fala de Suzy, aparecem as narrativas da espera (de sua amiga) e as narrativas da melhoria (a sua própria). Há ainda a narrativa da frustração que, em geral, diz respeito àqueles que "tinham casa boa" e não concebem a mudança para o apartamento como uma "melhoria de vida", como é o caso de Lucas, um dos vizinhos de Suzy. Cada uma dessas narrativas dissonantes - espera, meIhoria e frustração - dizem respeito às avaliações retrospectivas que os indivíduos fazem do montante de seu patrimônio. São os elementos empregados na construção de uma ou outra narrativa, que permitem compreender de quê o patrimônio era constituído - quantos imóveis e com quais características, levando em consideração os critérios de formação de preços próprios dos mercados informais - e como ele se encontra atualmente, com a obtenção de um apartamento.

Em segundo lugar, o relato ainda apresenta algumas estratégias empregadas pelos moradores, nos mercados imobiliários liminares. 0 processo de produção da "demanda social" passa pela classificação a que nos referimos anteriormente, mas também por táticas de autoenquadramento de alguns moradores. 
Dependendo da situação de moradia do indivíduo, essas estratégias são variadas. Locatários como Suzy podem participar de ocupações de propriedades ociosas e pleitear um apartamento; outros se endividam e compram os imóveis onde moram na favela, de modo a trocá-lo por um apartamento. Há famílias que empregam uma combinação de estratégias: dividem a casa onde todos moram juntos em unidades habitacionais menores ou distribuem membros por ocupações de propriedades, de modo a multiplicar o número de apartamentos recebidos. Mais uma vez, o que está em jogo com essas táticas é a construção ou recuperação de um patrimônio.

0 relato de Suzy nos permite, portanto, levantar uma hipótese acerca do mecanismo que garante a reprodução e mesmo agravamento do déficit habitacional. Como, no cadastro social, são os donos dos imóveis que ganham apartamentos em condomínios populares, a política habitacional, de modo não previsto, garante acumulação também no mercado informal. Quem tem mais casas ganha mais apartamentos. Não raro, inquilinos são despejados, para que membros das famílias dos donos de imóveis sejam cadastrados. Nem todos, ou muito poucos, conseguem ou têm a oportunidade de comprar um imóvel no mercado imobiliário liminar e garantir sua troca por um apartamento. Assim, os expressivos números de locatários em mercados informais não são atendidos pelo programa e acabam buscando moradia em ocupações ou outras favelas.

\section{Marcella Carvalho de Araújo Silva}

Universidade do Estado do Rio de Janeiro, Instituto de Estudos Sociais e Políticos, Departamento de Estudos Sociais. Rio de Janeiro/RJ, Brasil. marcella.caarsi@gmail.com

\section{Notas}

(1) Cf. Nota Pública da Rede Cidade e Moradia: https://raquelrolnik.wordpress.com/2014/11/10/ programa-minha-casa-minha-vida-precisa-ser-avaliado-nota-publica-da-rede-cidade-emoradia/

(2) Se ainda forem levadas em consideração as condições de habitação, ou o chamado déficit habitacional qualitativo, os números aumentam para 15,5 milhões de famílias. Segundo a Fundação João Pinheiro (2012), que faz os levantamentos de déficit habitacional no Brasil, há cinco critérios para o cálculo de déficit qualitativo: inadequação fundiária urbana, adensamento excessivo dos domicílios, cobertura inadequada, domićlios sem banheiro e carência de infraestrutura. 
(3) http://www.cartacapital.com.br/politica/como-nao-fazer-politica-urbana-3066.html

(4) Um aglomerado subnormal é, segundo definição desde 1987, “o conjunto constituído por 51 ou mais unidades habitacionais caracterizadas por ausência de título de propriedade e pelo menos uma das seguintes características: irregularidade das vias de circulação e do tamanho e forma dos lotes; e/ou carência de serviços públicos essenciais (como coleta de lixo, rede de esgoto, rede de água, energia elétrica e iluminação pública)" (IBGE, 2010).

(5) Ainda que precários, segundo os dados da Secretaria Municipal de Habitação do Rio de Janeiro, obtidos junto ao Observatório das Metrópoles, até julho de 2012 haviam sido contratadas 99.943 unidades habitacionais (doravante UH) para as três faixas de renda, em toda a Região Metropolitana do Rio de Janeiro, das quais 56.961 localizadas no município do Rio. Para a "faixa de interesse social", haviam sido contratadas 34.077 UH na RMRJ, das quais 27.077 distribuídas por 82 "condomínios populares" na capital. Desses 82 condomínios populares contratados, 48 estavam prontos até 2012. Segundo a classificação do Observatório das Metrópoles, 32 foram ocupados por famílias "removidas", 12 por famílias "sorteadas" e quatro ainda aguardavam ocupação.

(6) A discussão que se segue é parte da minha pesquisa de doutorado ainda em desenvolvimento.

(7) Gostaria de fazer um esclarecimento preliminar sobre o objeto deste artigo. Recorrentemente, as áreas de risco são contabilizadas nas estatísticas que pretendem denunciar a "retomada das remoções" no Rio (Azevedo e Faulhaber, 2014; Faulhaber, 2012; Comitê Popular Rio Copa e Olimpíadas, 2014). Como demonstro no meu estudo de caso, há inúmeros fatores arbitrários em jogo também nas remoções de áreas de risco. Contudo, não podemos negligenciar o fato de que a autoconstrução nem sempre garante condições de habitabilidade e que os mercados informais, muitas vezes, deixam moradores vivendo em situações precárias, problemas esses que a urbanização não é capaz de sozinha resolver. Ainda que controverso, já que no Rio ele está sendo usado como instrumento para remoções sem embasamento técnico, além de manter vários paralelos com o antigo BNH (Andrade, 2011), o PMCMV deve ser analisado em toda sua complexidade. Por todo o país, inúmeras ocupações de terras e propriedades ociosas são feitas com o objetivo explícito de pressionar prefeituras por cadastramento no PAC ou PMCMV (Cavalcanti, Blank e Fontes, 2012; Boulos, 2012), concebendo, pois, ambos os programas como formas de acesso à moradia. Trato neste artigo exclusivamente de um caso de área de risco, a partir do qual pretendo investigar as complexidades da discussão sobre moradia e especialmente dos mecanismos de administração da habitação de interesse social. Fica em aberto a questão se as dinâmicas por mim analisadas e as hipóteses que levanto são aplicáveis também a casos de "remoções olímpicas".

(8) Tendo em vista garantir o anonimato dos moradores que lutam, de diferentes formas, ou para permanecer em suas atuais moradias, ou para ter acesso à moradia digna, o nome da favela e de seus residentes e sua localização são omitidos.

(9) Como estratégia metodológica, enquadro as remoções como momentos críticos, que mobilizam as capacidades críticas dos atores de se posicionarem diante de uma controvérsia. Nesse sentido, a tematização da divergência como injustiça, a exigência de provas de justeza das medidas propostas (Boltanski e Thévenot, 2006) e a elaboração de projetos alternativos que contemplem o "bem de todos" (Werneck, 2012) compõem o regime de justificação das posições adotadas. 
(10) Segundo Elias (2000), as fofocas são um importante objeto da investigação sociológica, por tornarem evidentes os conflitos intra e intergrupos. No caso aqui analisado, as fofocas são uma forma de estabelecer as fronteiras entre a associação de moradores, endereçando a ela atitudes condenáveis, e, por contraste, construir o grupo da comissão de moradores, que estaria "de fato" interessado no "bem da comunidade".

(11) Em sua reflexão sobre Estados pós-coloniais, Benedict Anderson (2008) aponta os censos, os mapas e os museus como instrumentos fundamentais da produção e reprodução de narrativas nacionais dos novos países independentes. São eles, respectivamente, os responsáveis pela invenção de uma população, de um território, de uma história e patrimônio compartilhados, que embasam a atuação do Estado. É interessante perceber que, na luta pelo acesso à terra urbana, os membros da comissão de moradores mobilizem um recurso como o desenho de uma bandeira, a partir de elementos da história a mim narrada e materializada no CD que entreguei a essas lideranças, como instrumento de luta política. O que subjaz a essa estratégia é o discurso sobre a soberania de um grupo político sobre determinada porção de terra, com base na construção de uma narrativa comunitária.

(12) Uma das favelas em Curicica, Zona Oeste, onde trabalhei durante o programa Morar Carioca, ameaçada de remoção parcial pelas obras da Transolímpica, também instalou uma placa na sua entrada, declarando- se "condomínio".

(13) O verbo "edificar" é particularmente significativo, pois apresenta uma dimensão material - de construção, edificação de casas - e uma dimensão religiosa - entre os evangélicos, a missão de edificação diz respeito a projetos de vida.

(14) Instituto de Pesquisa e Planejamento Urbano e Regional, da Universidade Federal do Rio de Janeiro.

(15) Fundação Instituto Geotécnica do Estado do Rio de Janeiro.

(16) No primeiro semestre de 2015, os apartamentos de alguns desses moradores começaram a ser ocupados por outras famílias, no condomínio popular. Houve muita especulação de que o tráfico local estivesse autorizando as ocupações. De modo a garantir que os apartamentos que vistoriaram não fossem ocupados, alguns moradores da favela se mudaram antes de receber oficialmente as chaves.

(17) Sobre isso, cf. coletânea organizada por Maricato (1982).

(18) Cf. o número 10 da Coleção Habitare, intitulado Favela e mercado informal: a nova porta de entrada dos pobres nas cidades brasileiras (2009). O livro traz os primeiros resultados da pesquisa da Rede Infosolo, compilando dados sobre importantes capitais brasileiras.

(19) Cf. Lacerda e Melo (2009) sobre os mecanismos de formação de preços e dinâmicas de coordenação oferta e procura em mercados informais em Recife.

(20) Essa correlação não é necessária. Há muitos apartamentos vazios que aguardam a regularização da situação de sorteados ou suplentes de beneficiários. Eles geram enorme especulação nos condomínios e são uma das principais dúvidas que os moradores levam à equipe de trabalho social. Na percepção amplamente compartilhada, é "injusto" que haja apartamentos vazios tanto por opção pela não mudança por parte de moradores sorteados - que, em alguns casos, se beneficiam do cartão Minha Casa Melhor, para compra de R\$5mil em móveis, e alugam os imóveis -, como por demora em sorteio, já que muitos têm parentes ou conhecidos cadastrados e em filas de espera. 


\section{Referências}

ABRAMO, P. (2003). "A teoria econômica da favela: quatro notas sobre a localização residencial dos pobres e o mercado imobiliário informal”. In: ABRAMO, P. (org.). A cidade da informalidade: o desafio das cidades latino-americanas. Rio de Janeiro, Sette Letras.

(2009a). "O mercado informal do solo em favelas e a mobilidade residencial dos pobres nas grandes cidades: um marco metodológico". In: ABRAMO, P. (org.). Favela e mercado informal: a nova porta de entrada dos pobres nas cidades brasileiras. Porto Alegre, Antac. Coleção Habitare v. 10, pp. 14-47. Disponível em: http://issuu.com/habitare/docs/colecao_10/17. Acesso em: 15 dez 2015.

(2009b) (org.) Favela e mercado informal: a nova porta de entrada dos pobres nas cidades brasileiras. Porto Alegre, Antac. Coleção Habitare v. 10, pp. 14-47. Disponível em: http://issuu. com/habitare/docs/colecao_10/17. Acesso em: 15 dez 2015.

ABRAMO, P. e PULICI, A. (2009). "Vende-se uma casa: o mercado imobiliário informal nas favelas do Rio de Janeiro". In: ABRAMO, P. (org.). Favela e mercado informal: a nova porta de entrada dos pobres nas cidades brasileiras. Porto Alegre, Antac. Coleção Habitare v. 10, pp. 200-225. Disponível em: http://issuu.com/habitare/docs/colecao_10/17. Acesso em: 15 dez 2015.

ACSELRAD, H. (2010). Ambientalização das lutas sociais: o caso do movimento por justiça ambiental. Estudos Avançados, v. 24, n. 68, pp.103-119.

ALVES, J. e CAVENAGHI, S. (2004). Questões conceituais e metodológicas relativas a domicílio, família e condições habitacionais. I CONGRESSO DA ASSOCIAÇÃO LATINO AMERICANA DE POPULAÇÃO, ALAP. Minas Gerais, Caxambu, 18-20 de setembro.

ANDERSON, B. (2008). Comunidades Imaginadas. Reflexões sobre a origem e a difusão do nacionalismo. São Paulo, Companhia das Letras.

ANDRADE, E. (2011). Política Habitacional no Brasil (1964-2011): do "sonho da casa própria à minha casa, minha vida". Dissertação de Mestrado. Niterói, Universidade Federal Fluminense.

AZEVEDO, L. e FAULHABER, L. (2015). SMH 2016: Remoções no Rio Olímpico. Rio de Janeiro, Mórula.

BENJAMIN, C. (1988). A questão fundiária e as áreas de risco. In: PREFEITURA DO RIO DE JANEIRO. Revista da Secretaria Municipal de Desenvolvimento Social. Rio de Janeiro. pp.36-47.

BRASIL (1999). Programa Habitar Brasil/BID. Disponível em: http://www.cidades.gov.br/index. php?option=com_content\&view=article\&id=507:hbb\&catid=94\&/temid=126. Acesso em: 31 maio 2015.

(2007). Ministério das Cidades/Instituto de Pesquisas Tecnológicas - IPT Mapeamento de Riscos em Encostas e Margem de Rios. CARVALHO, C. S.; MACEDO, E. S. de e OGURA, A. T. (orgs.). Brasília, Ministério das Cidades/Instituto de Pesquisas Tecnológicas - IPT.

BOLTANSKI, L. e THÉVENOT, L. (2006). On Justification: economies of worth. Princeton, Princeton University Press.

BOULOS, G. (2012). Por que ocupamos? Uma introdução à luta dos sem teto. São Paulo, Scortecci. 
CAVALCANTI, M. (2010). S/morro varandão salão 3dorms: a construção social do valor em mercados imobiliários limiares. Antropolítica (UFF), v. 28, pp. 19-46.

(2014). "Threshold markets: the production of real estate value between the favela and the pavement". In: FISCHER, B.; MCCANN, B. e AYUERO, J. (2014). Cities from scratch: poverty and informality in urban Latin American. Duham e Londres, Duke University Press. Kindle edition.

(no prelo). "Survey do projeto de pesquisa 'A construção social, material e simbólica da dita "Barra Olímpica”, entre condomínios e quitinetes'”. In: CAVALCANTI, M.; FONTES, P. e BLANK, T. (2012). CCPL: Favela Fabril. Lincoln Institute of Land Policy Working Paper 49.

COMITÊ POPULAR RIO DA COPA E OLIMPÍADAS (2014). Megaeventos e violações dos direitos humanos no Rio de Janeiro.

DESROSIÈRES, A. (2002). The politics of large numbers. Cambridge/Massachussets, Harvard University Press.

ELIAS, N. (2000). Os estabelecidos e os outsiders. Sociologia das relações de poder a partir de uma pequena comunidade. Rio de Janeiro, Zahar.

FAULHABER, L. (2012). Rio maravilha: práticas, projetos políticos e intervenção no território no início do século XXI. Trabalho final de graduação. Niterói, Universidade Federal Fluminense. (http://issuu. com/lucas.faulhaber/docs/tfg_lucasfaulhaber).

FUNDAÇÃO JOÃO PINHEIRO (2012). Déficit habitacional no Brasil 2009 / Fundação João Pinheiro, Centro de Estatística e Informações. Belo Horizonte.

IBGE (2010). Censo demográfico 2010: Aglomerados subnormais - primeiros resultados. Rio de Janeiro, pp. 1-259.

(2011). Censo demográfico 2010. Aglomerados Subnormais: primeiros resultados. Disponível em: http://www.ibge.gov.br/home/presidencia/noticias/imprensa/pp ts/00000006960012162011001721999177.pdf. Acesso em: 31 maio 2015.

LACERDA, N. e MELO, J. (2009). “Mercado imobiliário informal de habitação na Região Metropolitana do Recife". In: ABRAMO, P. (org.). Favela e mercado informal: a nova porta de entrada dos pobres nas cidades brasileiras. Porto Alegre, Antac. Coleção Habitare v. 10, pp. 200-225. Disponível em: http://issuu.com/habitare/docs/colecao_10/17. Acesso em: 15 dez 2015.

MACHADO DA SILVA, L. A. (1967). A política na favela. Cadernos Brasileiros, ano IX, n. 41.

MAGALHÃES, A. et al. (2013). O mercado imobiliário de aluguéis em favelas do Rio de Janeiro: informalidades ou outras formas de formalidade? ENCONTROS NACIONAIS DA ANPUR. Anais. Disponívelem:http://unuhospedagem.com.br/revista/rbeur/index.php/anais/article/view/4529

MARICATO, E. (1982). A produção capitalista da casa (e da cidade) no Brasil industrial. São Paulo, Aurora.

MOTTA, E. (2014). Houses and economy in the favela. Vibrant - Virtual Brazilian Anthropology, v. 11, n. 1. Brasília, ABA. Disponível em: http://www.vibrant.org.br/issues/v11n1/eugeniamotta-houses-and-economy-in-the-favela/. Acesso em: 31 maio 2015.

TURNER, V. (1974). O processo ritual. Petrópolis, Vozes.

(1987). The anthropology of performance. Nova York, PAJ Publications. 
VALLADARES, L. (1978). Passa-se uma casa: análise do programa de remoção de favelas do Rio de Janeiro. Rio de Janeiro, Zahar.

WERNECK, A. (2012). "A contribuição de uma abordagem pragmatista da moral para a sociologia do conflito". In: MISSE, M. e WERNECK, A. (orgs.). Conflitos de (grande) interesse: estudos sobre crimes, violências e outras disputas conflituosas. Rio de Janeiro, Garamond.

Texto recebido em 31/maio/2015

Texto aprovado em 2/dez/2015 